\title{
Ability Training Methods of Postgraduates with Interest-oriented, Omni-directional and Diversified Resource Utilization and Plant Protection Professional Degree
}

\author{
Kaifa Guo ${ }^{1}$ Chenzhong Jin ${ }^{1, *}$ Yunyun Zhou ${ }^{1}$ Xiu Liu ${ }^{1}$ \\ ${ }^{1}$ Collaborative Innovation Center for Farmland Weeds Control, Hunan University of Humanities, Science and \\ Technology, Loudi, Hunan 417000, China \\ *Corresponding author. Email: Email: hnldjcz@sina.com
}

\begin{abstract}
With the rapid development of agriculture in the new era and the improvement of higher education level, there are higher requirements for the ability of postgraduates in the field of resource utilization and plant protection. This article mainly researches the ways to cultivate the ability of professional postgraduates in the field of interest-oriented, omni-directional and diversified resource utilization and plant protection, mainly including perfecting the curriculum system, improving teaching methods, cultivating postgraduates' self-learning and innovative awareness and capabilities, enhancing postgraduates' academic horizon and scientific research capabilities, implementing a dual tutor system as well as industry-university-research training mode, affecting postgraduates' academic attitude and scientific spirit, etc., so as to promote the realization of the goal of training postgraduates.
\end{abstract}

Keywords: Field of resource utilization and plant protection, Postgraduates, Training mechanism.

\section{INTRODUCTION}

The rapid development of China requires highquality talents with both ability and political integrity, and colleges and universities are gathering places for talents needed by the country, which have a significant impact on the development of the country and the improvement of overall national strength. Therefore, the country attaches great importance to the education and training of postgraduates in colleges and universities [1][2]. In the "Thirteenth Five-Year Plan for Academic Degrees and Postgraduate Education Development" issued by the Ministry of Education and the

*Funds: Research Project of Degree and Postgraduate Education Reform of Hunan University of Humanities, Science and Technology (Research on Multi-collaborative Training Mode of Postgraduate Innovation Ability Based on Scientific Practice), Practice Project of Hunan New Agricultural Science Research and Reform (XJT [2020] No. 94; XJT [2019] No. 291(925)), Research Project of Teaching Reform in Ordinary Colleges and Universities in Hunan Province (The Teaching Reform and Practice of Plant Pathology in Plant Production Against the Background of New Agricultural Science), RKJGZ1943)
Academic Degrees Committee of the State Council in January 2017, it has been put forward that one of the general ideas of postgraduate education is to cultivate innovative talents with collaboration between science and education and the integration of industry and education, and at the same time, the necessity to "reform the training mode and enhance the ability of innovation and practice has also been pointed out" [3][4]. The construction of an innovative country in the future is inseparable from postgraduates, and cultivating postgraduates with innovative abilities is crucial in the entire education process. The innovative ability of postgraduates can be divided into four parts: knowledge structure and learning ability, innovative awareness and problemfinding ability, scientific and innovative thinking and methods, and innovative practice and problemsolving ability.

In recent years, in the face of the accelerated globalization process and global climate change challenges, crop production has suffered more serious threats, such as invasion of dangerous alien 
species, frequent occurrence of destructive diseases, insects and crop smothering, successive cropping obstacles of crop, changes in the types of major plant diseases and insect pests, etc. [5]. The existence of agricultural scientific and technical personnel is of great significance, and they bear huge responsibilities. Postgraduates in the field of resource utilization and plant protection use a variety of theories and methods to protect target plants from harmful biological hazards or reduce the hazards below the economic threshold through comprehensive learning and application, so as to achieve the purpose of increasing crop yield and increasing farmers' income. The development of resource utilization and plant protection is one of the important links to ensure the healthy and sustainable development of agriculture [6]. Therefore, the cultivation of scientific and technological talents in the field of high-level resource utilization and plant protection is very crucial. However, the quality of postgraduate training is affected by a variety of factors such as subjective and objective factors. This article mainly researches the ways to cultivate the ability of professional postgraduates in the field of interestoriented, omni-directional and diversified resource utilization and plant protection, and provides theoretical and practical basis for cultivating plant protection professionals.

\section{OPTIMIZING THE TRAINING METHODS FOR PROFESSIONAL POSTGRADUATES IN THE FIELD OF RESOURCE UTILIZATION AND PLANT PROTECTION}

The training method of postgraduates in colleges and universities determines the knowledge structure, level and ability of talents, which should keep pace with the times, and the method of training talents should be continuously revised and improved with the development of the times. The training plan is an important basis for the implementation of student training, which should be feasible, forward-looking, in line with the student's training goals, and more importantly, embody a well-structured and focused practical ability training system. A reasonable course setting is conducive to the construction of a reasonable knowledge structure for postgraduates, enabling postgraduates to cultivate their own innovative abilities during the course of study and stimulating their sense of innovation. The field of resource utilization and plant protection in Hunan University of Humanities, Science and Technology invites well-known scholars and senior executives and experts of enterprises and industries in the field of resource utilization and plant protection in China from China Agricultural University, Hunan Plant Protection and Quarantine Station, Hunan Haili High-tech Industrial Group, Plant Protection Institute of Hunan Academy of Agricultural Sciences, Hunan Agricultural University, etc. to participate in the improvement of professional talent training programs, the formulation of training objectives and the selection of the scope of the syllabus, so as to develop a programmatic document for cultivating talents that meet the needs of the industry.

\subsection{Improving the Curriculum System}

The training program should adapt to local agricultural development, aim at industry development trends, and focus on talent demand specifications. It is necessary to cultivate the operational and practical ability of postgraduates. Public elective courses should be set up with more cross-professional, methodological, implemental, and practical courses; the teaching content should be continuously updated, so that the curriculum has both depth and breadth and can reflect the cuttingedge and latest scientific research results of the subject field; information retrieval courses should also be added to strengthen the training of postgraduates' information acquisition ability and improve the information literacy of postgraduates; according to the characteristics of the school and the local area, it is needed to construct a distinctive curriculum system and cultivate talents suitable for the needs of social and economic development so as to promote employment.

\subsection{Improving Teaching Methods}

Teachers can teach postgraduates in the form of seminars, group discussions and lectures, as well as MOOCs and flipped classrooms. Case teaching, enlightening teaching, inquiry teaching, and multidiscipline integration can be adopted actively; the enthusiasm of postgraduates can be aroused to participate in academic discussions through academic reports, broaden academic horizons, and improve academic level; a postgraduate course information platform can be opened up to realize the sharing of teaching resources. 


\subsection{Setting up Teaching Content Reasonably}

In terms of teaching content, it is necessary to pay equal attention to theory and practice, and to set up corresponding courses according to the professional characteristics of the field of resource utilization and plant protection, so that it can be better applied to the scientific research practice of postgraduates; in practical teaching, it is necessary to establish a school-enterprise joint training method, so that students at school can enter the front line of work and agricultural production, and get out of the situation of only staying in book theories. This will not only enable students to apply the knowledge they have learned in school to practice, but also cultivate their ability to discover and solve problems in practice, and provide factual support for theoretical and knowledge innovation.

\section{CHANGE OF SELF-INNOVATION CONSCIOUSNESS OF POSTGRADUATES}

For a long time, the general public have insufficient understanding of agronomy subjects, and believe that in the end, after learning agronomy, they still need to be engaged in agriculture. Students in the field of resource utilization and plant protection are all affected by the word "agriculture" and have a serious ideological burden[8]. Postgraduates in the field of resource utilization and plant protection should change this thought and actively improve their own learning ability and scientific research and innovation ability. Relying on the research conditions and platforms of the provincial 2011 Collaborative Innovation Center of Hunan University of Humanities, Science and Technology "Hunan Collaborative Innovation Center for Farmland Weed Prevention and Control", the provincial application characteristic discipline "Plant Protection" and the provincial key laboratory "Pesticide Harmless Application Laboratory", compound application-oriented talents in Hunan who have sentiments and practical ability to "understand agriculture, love rural areas, and love farmers" should be cultivated.

\subsection{Cultivating Postgraduates' Self- learning and Innovative Awareness and Capabilities}

Postgraduates must correct their learning attitude and motivation for postgraduate studies, strengthen self-learning ability and the ability to accept knowledge, be clear about their learning goals and have the habit of making learning plans to ensure that they will not lose their way in the long way to study. Postgraduates should be good at using various channels to collect cutting-edge information in the field of resource utilization and plant protection, grasp the recent news in the field, enhance the ability to read documents, summarize and write, and communicate with their tutors about their own ideas in a timely manner; they should actively participate in the topics declaration and research result display activities; they need to actively think, take the initiative to find ways to acquire knowledge, and transform the digestion and absorption of knowledge into their own energy storage; they should actively participate in professional skills competitions, innovation and entrepreneurship competitions, and summer social production practice activities to enhance their professional cognitive practice, expand professional cognitive horizons, and increase professional interest.

\subsection{Enhancing the Academic Horizon and Scientific Research Ability of Postgraduates}

The fundamental purpose of conducting postgraduate academic exchange activities is to increase knowledge reserves, broaden the breadth of academic horizons, and enhance scientific research and creativity. Postgraduates should participate in academic exchanges between Chinese societies, industry associations, and universities; the school and college need to actively organize academic exchange activities to understand the latest cutting-edge developments in this field; schools also should hire well-known domestic and foreign experts, industry experts, and corporate technology leaders to give short-term lectures, promote the cultivation of postgraduates' scientific research and innovation awareness, innovative thinking and ability, and create a strong campus academic research atmosphere. These activities not only enrich the postgraduate study career, but also enhance the academic innovation ability of postgraduates.

\section{CHANGE OF TUTORS' INSTRUCTION METHODS}

Tutors of postgraduates shoulder the important task of cultivating cutting-edge technical talents and are an important force in the cultivation of 
postgraduates in China. In addition to improving their own scientific research capabilities, tutors must also improve their guidance, organization, and planning capabilities. The tutor team is the prerequisite and guarantee for cultivating high-level postgraduates. Without the high-level "guidance" of the tutor, let alone the "achievements" of the cultivation of postgraduates' innovative ability[8]. Therefore, it is necessary to strengthen the management and restraint of tutors, and strictly require the quality of tutors. In addition to the regular review of the scientific research results of tutors, attention must be paid to the construction of the moral level of the tutors. What's more, the evaluation mechanism and reward and punishment system for the tutors also need to be perfected. It is needed to establish a perfect training system for tutors. Tutors need to continue to learn to improve their ability to guide and train postgraduates. The school should actively support the construction of scientific research platforms, and tutors should strengthen academic exchanges to ensure that they understand the most cutting-edge knowledge and development directions of related majors in the first time.

\subsection{Implementing a Dual Tutor System}

Under the framework of the professional postgraduates' training program, it is necessary to formulate targeted training plans for different students. Tutors inside and outside the school should frequently communicate the problems in the student training process and formulate corresponding countermeasures in real time, so that the trained students have the corresponding professional knowledge and practical ability. Tutors should actively guide students to combine course learning with scientific research, so that students can find happiness in learning knowledge in scientific research practice. It is needed to train students to discover, analyze and solve problems. In the exchanges between teachers and students to discuss problems, students can improve their personal abilities such as screening scientific research topics, scientific experiments, practical operational abilities, analysis and demonstration, and statistics and data analysis. Finally, postgraduates who can seek truth from facts and be able to solve practical problems will be cultivated.

\subsection{Adopting the Industry-University- Research Training Mode}

The school should train postgraduates in accordance with the model of "three doubles, four modules and seven stages of learning", and implement the school-enterprise "dual guidance and multiple teachers" and "alternation of dual stages" multi-post practice training. When cultivating postgraduates in the field of resource utilization and plant protection, the school should cooperate with Hunan Academy of Agricultural Sciences (Plant Protection Institute of Hunan Academy of Agricultural Sciences), Hunan Haili High-tech Industrial Group, Hunan Plant Protection and Quarantine Station, etc., and utilize the scientific research platforms, pilot test bases, and practice bases of the two parties to jointly cultivate postgraduates in the field of resource utilization and plant protection. Through the cultivation of industry-university-research training mode, students can personally contact equipment, integrate into production, master advanced production technology, and improve practical ability, which will be helpful for them to understand the market as soon as possible, and adapt to and integrate into society.

\subsection{Influencing Students Through Academic Attitude and Scientific Spirit}

Tutors are the best role models for students, and their attitude towards work and scientific research directly affects students. Therefore, tutors need to maintain a rigorous academic attitude and scientific spirit, work hard, activate their innovative thinking, and inspire students. Tutors should treat students equally, communicate more with students, and be both teachers and friends, so that they can understand the students' ideological trends in time and improve the efficiency of guidance.

\section{CONCLUSION}

China is a big agricultural country, and agricultural postgraduate talents are very important to the country's development. This article proposes a number of ways to develop the ability of postgraduates in the field of resource utilization and plant protection in local transformation development universities. The comprehensive ability training of postgraduates involves many aspects, generally including professional knowledge, scientific research and academic ability, social practice, thinking ability and personal cultivation. To create excellent postgraduates in the field of resource utilization and plant protection, it is necessary to cultivate and exercise the abovementioned various abilities of them. In the process of postgraduate training, it is inseparable from the 
hard work of the postgraduates themselves, the careful cultivation of the tutors, the full investment of the training institutions and the harmonious atmosphere of social inclusion.

With the guidance of a reasonable training plan, postgraduates majoring in the field of resource utilization and plant protection of Hunan University of Humanities, Science and Technology participate in scientific research projects, enterprise production practice, production technology innovation, and product promotion under the guidance of dual tutors inside and outside the school. These activities improve the ability of postgraduates to solve actual production problems, and at the same time enable them to have the ability to research independently and adapt to social production and economic development. As a result, the employment rate of students and the recognition of industry and enterprise have increased. The cooperation between on-campus and off-campus tutors has also improved teachers' teaching and scientific research capabilities and the level of serving local economic development.

\section{AUTHORS' CONTRIBUTIONS}

Chenzhong Jin is responsible for experimental design, Yunyun Zhou analysed data, Kaifa Guo wrote the manuscript, and Xiu Liu contributed to revising and editing

\section{REFERENCES}

[1] Gao Yan. Thoughts on the cultivation of postgraduates' scientific research ability and innovation ability $[\mathrm{J}]$. Journal of Liaoning Institute of Technology (Social Science Edition), 2018, 20(05): 107-109. (in Chinese)

[2] Wang Yongjie, Liu Jingju, Yang Guozheng. How to Direct Postgraduates to do Innovative Research under New Circumstance [J], Education Teaching Forum, 2019(43): 3-5. (in Chinese)

[3] Zheng Jun, Zhu Jing. Evaluation and Strategy Analysis of Postgraduate Innovation Ability Training under CIPP Mode [J]. Journal of Shenyang University (Social Science Edition), 2019, 21(05): 591-596. (in Chinese)

[4] Ouyang Haibo, Huang Jianfeng, Li Cuiyan, Fei Jie, Cao Liyun, Yin Lixiong, Liu Hui. Local University Graduate Student Innovation Ability Training Mode of Multiple
Cooperative Exploration and Practice [J]. Education Teaching Forum, 2018(15): 118120. (in Chinese)

[5] Luo Jinxiang, Zhang Yongqiang, Yang Zhenguo. On Innovative Capacity of College Students Majoring in Plant Protection [J]. Journal of Southwest China Normal University (Natural Science Edition), 2014, 39(01): 172-176. (in Chinese)

[6] Wang Jia, Liu Yinghong. Exploration on Cultivating Comprehensive Capability of Graduate Student Majoring in Plant Protection [J]. Journal of Southwest China Normal University (Natural Science Edition), 2015, 40(07): 199-204. (in Chinese)

[7] Sun Xianchao, Wang Jinjun, Liu Huai, Ding Wei, He Lin. Innovation and Application of Teaching System of Plant Protection [J]. Journal of Southwest China Normal University (Natural Science Edition), 2013, 38(01): 131-134. (in Chinese)

[8] Gui Qing, Zhang Xiusheng, Yu Shouchao. Cultivation and training of scientific research and innovation ability of applied professional academic postgraduates in local colleges and universities — Taking the landscape architecture major of Liaocheng University as an example [J]. Shandong Education (Higher Education), 2019(Z1): 113-115. (in Chinese) 